\title{
An appetitive conditioned stimulus enhances fear acquisition and impairs fear extinction
}

\author{
Hiu T. Leung, Nathan M. Holmes, and R. Frederick Westbrook \\ School of Psychology, University of New South Wales, Sydney 2034, Australia
}

\begin{abstract}
Four experiments used between- and within-subject designs to examine appetitive-aversive interactions in rats. Experiments 1 and 2 examined the effect of an excitatory appetitive conditioned stimulus (CS) on acquisition and extinction of conditioned fear. In Experiment 1, a CS shocked in a compound with an appetitive excitor (i.e., a stimulus previously paired with sucrose) underwent greater fear conditioning than a CS shocked in a compound with a neutral stimulus. Conversely, in Experiment 2, a CS extinguished in a compound with an appetitive excitor underwent less extinction than a CS extinguished in a compound with a neutral stimulus. Experiments 3 and 4 compared the amount of fear conditioning to an appetitive excitor and a familiar but neutral target CS when the compound of these stimuli was paired with shock. In each experiment, more fear accrued to the appetitive excitor than to the neutral CS. These results show that an appetitive excitor influences acquisition and extinction of conditioned fear to a neutral CS and itself undergoes a greater associative change than the neutral CS across compound conditioning. They are discussed with respect to the role of motivational information in regulating an associative change in appetitive-aversive interactions.
\end{abstract}

Pavlovian conditioned fear in laboratory rodents is widely used to study the substrates of learning and memory in the mammalian brain. One reason for the use of this model is that conditioned fear is thought to contribute to anxiety disorders, such as panic, posttraumatic stress, social, and specific phobias (Rosen and Schulkin 1998). A second reason is that extinction of this fear is a goal of exposure-based treatments of these disorders (VanElzakker et al. 2014). A standard protocol to produce conditioned fear in rodents consists in pairings of a relatively innocuous stimulus, such as a noise, with an innate source of danger, typically brief but aversive foot shock. One or a few such pairings produces an excitatory association between the noise [conditioned stimulus (CS)] and the aversive foot shock [unconditioned stimulus (US)]. The consequence of this association is that subsequent presentations of the CS elicit defensive responses (immobility or freezing, potentiated startle, analgesia, changes in heart rate and blood pressure) indicative of fear in people. Extinction consists in repeated presentations of the CS in the absence of the US. Fear responses decline across these presentations and eventually cease. This decline and cessation of fear responses to the CS is not due to the progressive erasure of its association with the US. Fear restoration phenomena such as renewal, reinstatement, and spontaneous recovery show that at least some of the original CS-US association survives extinction despite the fact that the CS failed to elicit fear responses. These phenomena imply that extinction involves new learning that inhibits retrieval of the CS-US association and/or its expression in fear responses (Delamater and Westbrook 2014).

A question of both theoretical and translational importance is the circumstances under which fear acquisition and fear extinction occur: What conditions enhance or impair the formation of the association between the CS and the aversive US, and what are those that enhance or impair the inhibitory learning that underlies fear extinction? It has been known for some time that the de-

\section{Corresponding author: f.westbrook@unsw.edu.au}

Article is online at http://www.learnmem.org/cgi/doi/10.1101/lm.040337. 115. velopment of fear responses to a CS depends on its relation to the aversive US as well as the relation between other concomitantly cues and that US. For example, when a novel stimulus (e.g., a light) is conditioned in a compound with a second stimulus (e.g., a noise), learning to fear the light is impaired or blocked if its partner noise has been pretrained to signal the aversive US (Kamin 1968), and enhanced (or superconditioned) if the partner noise has been pretrained to signal that the aversive US will not occur (Rescorla 1971). These and other results led to theories which propose that associative formation is regulated by a prediction error, that all the cues present on a conditioning trial are used to calculate the error, and that the size of the error determines the amount of associative formation (e.g., Rescorla and Wagner 1972; Pearce and Hall 1980; Wagner 1981). According to such theories, the association between the light and the aversive US was impaired in the blocking protocol because the pretrained excitatory noise correctly predicted the occurrence of the shock US across the compound trials, hence, the error signal was small; and the association between the light and the aversive US was enhanced in the so-called superconditioning protocol because the pretrained inhibitory noise wrongly predicted that the shock US would not occur across the compound trials, hence, the error signal was large.

Error correction theories also explain the effects of concomitantly present cues on extinction of conditioned fear. Specifically, as the error signal in extinction is triggered by the absence of an expected aversive US, these theories predict that the effects of excitatory and inhibitory CSs on extinction of conditioned fear will be opposite to their effects on fear acquisition. Just such results have been observed. Whereas the presence of an already conditioned CS blocks acquisition of conditioned

(C) 2016 Leung et al. This article is distributed exclusively by Cold Spring Harbor Laboratory Press for the first 12 months after the full-issue publication date (see http://learnmem.cshlp.org/site/misc/terms.xhtml). After 12 months, it is available under a Creative Commons License (AttributionNonCommercial 4.0 International), as described at http://creativecommons. org/licenses/by-nc/4.0/. 
fear to a target CS, it has been shown to enhance extinction of fear to an already conditioned CS (Leung and Westbrook 2010; see also Wagner and Rescorla 1972). Conversely, whereas the presence of an aversive inhibitor enhances fear conditioning to a target CS, it has been shown to impair extinction of fear to an already conditioned CS (Soltysik et al. 1983; McConnell and Miller 2010).

Acquisition of fear to a target CS is also regulated by the presence of an excitatory appetitive CS (one pretrained to signal an appetitive US). According to error correction theories, when a compound composed of a novel target CS and an excitatory appetitive CS is paired with shock, the error signal produced by the omission of the expected US and the delivery of the unexpected shock is especially large, and hence, fear conditioning to the target CS increased. Just this result has been obtained. Dickinson (1977) exposed one group of rats to pairings of a noise and an attractive US (food pellets) and a second group to semirandom presentations of the noise and the food US. Then both groups were exposed to pairings of a light-noise compound and aversive footshock and tested for fear of the light (suppression of food-reinforced lever pressing). Dickinson reported that the light elicited more fear when conditioned in a compound with the noise that had been paired with the attractive US than with the randomly presented noise. The conditioned appetitive excitor in Dickinson's experiment had functioned like the conditioned fear inhibitor in Rescorla's (1971) experiment: The presence of either type of CS had enhanced fear conditioning of their novel partner in a shocked compound. However, it remains to be determined whether this parallel in the effects of an appetitive excitor and a fear inhibitor extends to the case of fear extinction. That is, whether an appetitive excitor functions like a conditioned fear inhibitor (e.g., McConnell and Miller 2010) to impair or block extinction of a fear CS across nonshocked exposures to the compound.

The present experiments used between- and within-subject designs to provide a further examination of the role played by error correction mechanisms in appetitive-aversive interactions. Experiments 1 and 2 examined the effect of an excitatory appetitive CS on acquisition and extinction of conditioned fear. The aim of Experiment 1 was to confirm that an appetitive excitor [a CS which signaled an attractive US (sucrose)] enhanced fear conditioning (measured by freezing) to its novel partner in a shocked compound (Dickinson 1977). Experiment 2 examined whether the appetitive excitor blocks extinction of a fear CS across nonshocked presentations of the compound. Evidence for enhanced conditioning of fear and blocking of fear extinction to a target CS by an appetitive excitor would be consistent with the proposal that associative change in fear conditioning and extinction is regulated by the discrepancy between the actual outcome of a trial (shock or no shock) and that predicted by all the cues present on a trial: the presence of the appetitive excitor increases the size of the error across shocked exposures to the compound, hence fear conditioning to the target CS is increased, and decreases the size of the error across nonshocked exposures to the compound, hence, extinction of the target CS is decreased. The final experiments examined whether the amount of associative change to the elements of a shocked compound is also regulated by the discrepancy between the actual outcome of a trial and that predicted by each element of the compound. If so, when an appetitive excitor and a neutral stimulus are shocked in a compound, more associative changes should accrue to the appetitive excitor because the actual outcome of a trial (aversive shock) is more discrepant from what the appetitive excitor predicts (attractive sucrose) than what is predicted by the neutral stimulus (nothing). Experiments 3 and 4 addressed this question using the compound test procedure (Rescorla 2000).

\section{Results}

\section{Experiment 1}

This experiment used a between-group design to examine the effect of an appetitive CS on fear conditioning of a novel CS across shocked exposures to the compound. Moderately hungry rats were first trained in an appetitive discrimination procedure where an appetitive US (sucrose) was delivered in the presence of one visual stimulus (A) but not of a second (B). Rats in one group were then exposed to pairings of a compound composed of $\mathrm{A}$ and a novel auditory stimulus (X) and foot shock, while those in a second group received pairings of a BX compound and footshock. Finally, rats in both groups were tested for fear (freezing) of $\mathrm{X}$. The design is shown in Table 1 . The expectation was that $\mathrm{X}$ would elicit more freezing when shocked in a compound with the CS that had been paired with sucrose (A) than with the CS (B) presented alone (Dickinson 1977).

Initial appetitive discrimination training proceeded smoothly. As shown in Figure $1 \mathrm{~A}$, by the final trials on day 5 , the mean percent time spent in magazine during the reinforced $\mathrm{A}$ stimulus was substantially greater than that during the nonreinforced B. This difference was statistically significant, $F_{(1,15)}=$ 117.2, $P<0.00001, \eta_{\mathrm{p}}^{2}=0.89,95 \% \mathrm{CI}=[2.3,3.4]$. However, it is important to note that the difference does not provide an unambiguous measure of the magazine approach elicited by A as distinct from the approach elicited by the sucrose, which occurred during the presentation of A. The levels of freezing over the course of fear conditioning on day 6 are shown in Figure 1B. Freezing responses developed more rapidly to the AX compound in Group Super than to the BX compound in Group Control, $F_{(1,14)}=$ $10.4, P<0.01, \eta_{\mathrm{p}}^{2}=0.43,95 \%$ CI $[0.3,1.6]$. There was no significant difference between the groups during the pre-CS periods, $F<1$. Figure $1 \mathrm{C}$ shows the levels of freezing on day 7 when $\mathrm{X}$ was tested alone. Averaged across all test presentations, $\mathrm{X}$ elicited more freezing responses in Group Super than in Group Control, $F_{(1,14)}=11.3, P<0.01, \eta_{\mathrm{p}}^{2}=0.45,95 \%$ CI $[0.5,2.3]$. No significant difference was observed during the pre-CS period, $F<1$.

These results show that a novel CS, X, elicited more freezing when it had been shocked in a compound with a CS, A, that had been paired with an appetitive US (sucrose) than with a CS, B, whose presentations had not been followed by sucrose. These results with freezing confirm those reported by Dickinson (1977) who found that a novel CS elicited more conditioned suppression when it had been shocked in a compound with a CS paired with food than with one that had been presented in a random relation to food.

There are two additional points worth noting. The first is that freezing developed more rapidly to AX than BX in Stage 2. This finding was unexpected. To be sure, the more rapid development of freezing to $\mathrm{AX}$ is consistent with the proposal that the presence

Table 1. Designs of Experiments 1 and 2

\begin{tabular}{lccc}
\hline Experiment 1 & & & \\
\hline Group & Stage 1 & Stage 2 & Stage 3 \\
\hline Super & A-sucrose, B- & AX-shock & X- \\
Control & A-sucrose, B- & BX-shock & X- \\
\hline
\end{tabular}

Experiment 2

\begin{tabular}{lllcc}
\hline Group & Stage 1 & Stage 2 & Stage 3 & Stage 4 \\
\hline Protect & A-sucrose, B- & X-shock & AX- & X- \\
Control & A-sucrose, B- & X-shock & BX- & X-
\end{tabular}

Note: $A$ and $B$ are visual stimuli (flashing light and steady light, counterbalanced). $X$ is an auditory stimulus. 

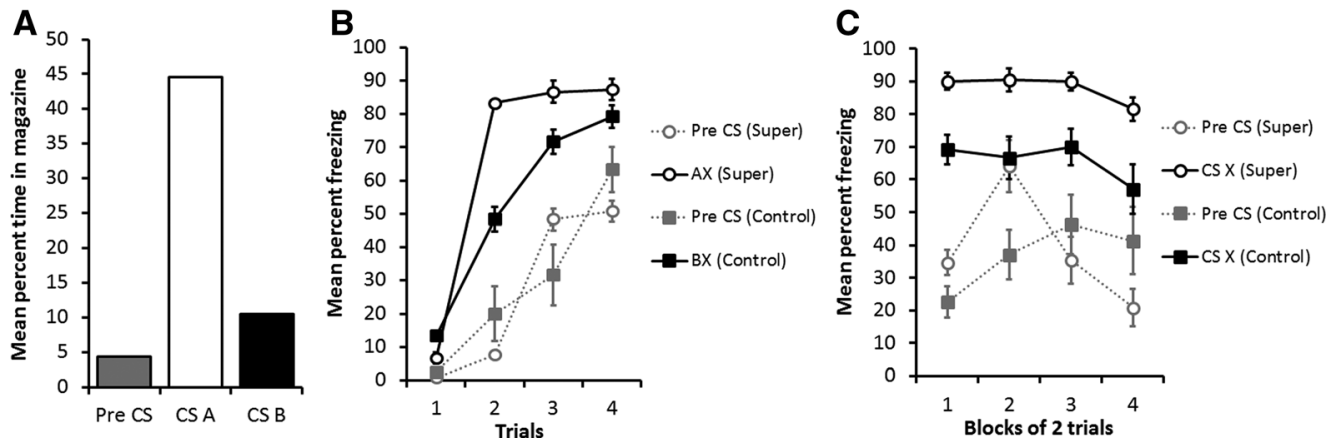

Figure 1. Results of Experiment 1. The mean percentage of time spent in magazine on the final trials of Stage 1 appetitive conditioning to conditioned stimuli (CSs) $A$ and $B$ and in the 30 -sec pre-CS periods $(A)$. The mean percentage of freezing during Stage 2 fear conditioning to the AX and BX compounds and in the 30-sec pre-CS periods by Groups Super and Control (B). The mean percentage of freezing during Stage 3 test to CS X and in the 30-sec pre-CS periods by Groups Super and Control (C). All error bars shows 2 standard errors of the mean.

of the appetitive A increased the size of the error signal elicited by the shock US, thereby increasing the amount of associative change to its $\mathrm{X}$ associate relative to the change accruing to $\mathrm{X}$ shocked in a compound with the control stimulus B. However, it was also expected that the association between $\mathrm{A}$ and the appetitive US would have interfered with expression of the new associations formed across shocked exposures to the AX compound. This did not occur. In fact, subsequent experiments provide evidence that the appetitive A undergoes greater change than the control stimulus $\mathrm{B}$ across shocked exposures to an $\mathrm{AB}$ compound, raising the possibility that the more rapid development of freezing to AX than BX in Stage 2 was due to greater change to both A and X across the shocked exposures. The second point is that the present differences in the test levels of freezing to $\mathrm{X}$ fear conditioned in a compound with the appetitive excitor, $\mathrm{A}$, versus in a compound with the control stimulus, B, do not necessarily reflect superconditioning of $\mathrm{X}$ by the appetitive $\mathrm{A}$. In fact, a previous investigation of so-called superconditioning of fear to a target $\mathrm{X}$ by an aversive inhibitor failed to detect any difference between the levels of this fear and that accruing to a target $\mathrm{X}$ conditioned in isolation (Navarro et al. 1989). It remains to be determined whether the enhanced conditioning of $\mathrm{X}$ by the appetitive A (observed in the present experiment) is in fact greater than that which would have accrued to $\mathrm{X}$ conditioned in isolation (for a further discussion of this point, see Urushihara et al. 2005).

\section{Experiment 2}

A CS that has signaled the nonoccurrence of footshock (an aversive inhibitor) protects a separately conditioned fear CS from ex- tinction when the two are presented in a nonshocked compound (e.g., McConnell and Miller 2010). The present experiment examines whether a CS that has signaled the presence of sucrose (an appetitive excitor) likewise protects a separately conditioned fear CS from extinction across nonshocked presentations of the compound. The design consisted in exposing rats to a discrimination where sucrose was paired with one visual CS, A, but not with a second, B. All rats were then exposed to pairings of a third, auditory CS, X, and shock. Subsequently, half of the rats received nonshocked exposures to $\mathrm{X}$ in a compound with A (Group Protect), and the other half received nonshocked exposures to $\mathrm{X}$ in a compound with B (Group Control). Finally, rats in both groups were tested for fear of $\mathrm{X}$. The design is shown in Table 1.

Initial appetitive discrimination training was uneventful. As shown in Figure 2A, by the final trials on day 5, the mean percent time spent in the magazine during the reinforced A stimulus was substantially greater than that during the nonreinforced $\mathrm{B}$. This difference was statistically significant, $F_{(1,15)}=117.2, \quad P<$ $0.00001, \eta_{\mathrm{p}}^{2}=0.89,95 \%$ CI $[2.1,3.2]$. Stage 2 fear conditioning also proceed smoothly. By the final fear conditioning trial, the mean levels of freezing to the CS was $91.6 \%$ for Group Protect and $95.0 \%$ for Group Control. There was no significant difference between these levels of freezing, $F<1$.

The levels of freezing across the nonshocked compound presentations on days 7 and 8 are shown in Figure 2B. Averaged across all trials, freezing to the dangerous $\mathrm{X}$ was suppressed more by $\mathrm{A}$ in Group Protect than by B in Group Control, $F_{(1,14)}=21.7, P<$ $0.005, \eta_{\mathrm{p}}^{2}=0.61,95 \%$ CI $[1.5,4.1]$. There was no significant difference in pre-CS responding, $F<1$. This suppression of $\mathrm{X}$ by $\mathrm{A}$ is consistent with the proposal that appetitive stimuli have
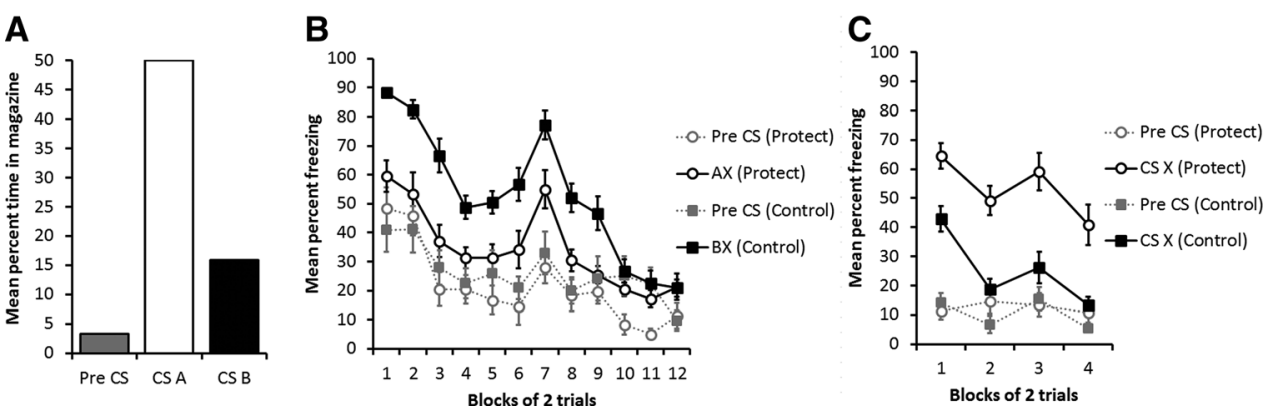

Figure 2. Results of Experiment 2. The mean percentage of time spent in magazine on the final trials of Stage 1 appetitive conditioning to conditioned stimuli (CSs) A and B and in the 30-sec pre-CS periods ( $A$ ). The mean percentage of freezing during Stage 3 fear extinction to the AX and BX compounds and in the 30-sec pre-CS periods by Groups Protect and Control (B). The mean percentage of freezing during Stage 4 test to CS X and in the 30-sec pre-CS periods by Groups Protect and Control (C). All error bars shows 2 standard errors of the mean. 
properties antagonistic or inhibitory to aversive stimuli. The test results on day 9 are shown in Figure 2C. The statistical analysis confirmed what is clear in the figure: Averaged across all test presentations, $\mathrm{X}$ elicited significantly more freezing in Group Protect than in Group Control, $F_{(1,14)}=56.7, P<0.00001, \eta_{\mathrm{p}}^{2}=0.80$, $95 \%$ CI $[2.7,4.8]$. There were no significant differences between the groups in the levels of freezing during the pre-CS periods, $F<1$.

These results show that the presence of the CS, A, that had been paired with sucrose not only reduced the levels of freezing elicited by the dangerous $\mathrm{X}$ but also protected $\mathrm{X}$ from extinction across the nonshocked $\mathrm{AX}$ presentations relative to the effect on $\mathrm{X}$ of a CS, B, whose presentations had not been followed by sucrose. Taken together, the contrasting effects of the appetitive excitor on fear conditioning and fear extinction challenge attentional explanations of appetitive-aversive interactions. If the appetitive excitor, A, entered Stage 2 commanding more attention than the control stimulus, B, as anticipated by one type of theory (e.g., Mackintosh 1975), it should have been more effective in reducing both conditioning to $\mathrm{X}$ in Experiment 1 and extinction of $\mathrm{X}$ in Experiment 2; conversely, if A commanded less attention than $\mathrm{B}$, as could be assumed by a second type of theory (e.g., Pearce and Hall 1980), it should have been less effective in overshadowing conditioning to $\mathrm{X}$ in Experiment 1 and extinction of $\mathrm{X}$ in Experiment 2 . Instead, the contrasting effect of an appetitive excitor on acquisition and extinction of conditioned fear to $\mathrm{X}$ can be interpreted to mean that such a CS functions like an aversive inhibitor, enhancing fear of a novel CS (Rescorla 1971) and blocking extinction of an already conditioned fear CS (McConnell and Miller 2010).

\section{Experiment 3}

The results of Experiment 1 showed that fear conditioning to a novel target CS, X, was enhanced when it was shocked in a compound with an appetitive excitor, A, compared to when it was shocked in a compound with an equally familiar stimulus lacking appetitive properties, $B$. The error signal produced by the presence of $A$ in the shocked compound was greater than that produced by the presence of $B$, suggesting that an associative change in such appetitive-aversive interactions is mediated by a total or common error term. The question addressed in this experiment is whether an associative change in appetitive-aversive interactions is also regulated by individual error terms; specifically, whether more changes accrue to the CS that had been paired with sucrose, A, than to the CS presented alone, B, across shocked exposures to the compound. The experiment used the compound test procedure (Rescorla 2001) to examine this question. The design consisted in training four CSs, two visual and two auditory. The two stimuli within a modality were each paired with sucrose, A+ and $\mathrm{C}+$, while presentations of either stimulus in the other modality were not followed by sucrose $(\mathrm{B}-$ and $\mathrm{D}-$ ). If tested with compounds composed of $\mathrm{AD}$ and $\mathrm{BC}$, then the response would be equivalent, as each compound contains an element paired with sucrose (A and C) and an element not paired with sucrose (B and D). However, this did not occur. Rather, rats received shocked exposures to an $\mathrm{AB}$ compound and were then tested with the $\mathrm{AD}$ and $\mathrm{BC}$ compounds. If associative change in appetitive-aversive interactions is just regulated by a total error term, then the response to the $\mathrm{AD}$ and $\mathrm{BC}$ compounds will again be equivalent as the change to $\mathrm{A}$ and $\mathrm{B}$ across the shocked exposures to the $\mathrm{AB}$ compound will be equal. If, however, a change is also regulated by the associative values of the CSs when they enter the compound conditioning, then more changes will accrue to the appetitive A than the equally familiar B, and freezing will be greater to $\mathrm{AD}$ than to $\mathrm{BC}$. The design is shown in Table 2.
Table 2. Designs of Experiments 3 and 4

\begin{tabular}{lcc}
\hline & Experiment 3 & \\
\hline Stage 1 & Stage 2 & Stage 3 \\
\hline A-sucrose & AB-shock & AD- \\
B- & & BC- \\
C-sucrose & & \\
D- & & Stage 3 \\
\hline Experiment 4 & Stage 2 & \\
Stage 1 & AB-shock & AD- \\
A-sucrose & CD- & BC- \\
B- & & \\
C-sucrose & & \\
\hline
\end{tabular}

Note: A, B, C, and D are conditioned stimuli (tone, clicker, flashing light, and steady light, counterbalanced).

The initial appetitive discrimination training proceeded smoothly. As shown in Figure 3A, by the final trials on day 9, the mean percent time spent in magazine during the reinforced $A$ and $C$ presentations was substantially greater than that during the nonreinforced $\mathrm{B}$ and $\mathrm{D}$ presentations. The greater response to $\mathrm{A}$ and $\mathrm{C}$ than to $\mathrm{B}$ and $\mathrm{D}$ was statistically significant, $F_{(1,15)}=$ $327.6, P<0.00001, \eta_{\mathrm{p}}^{2}=0.96,95 \%$ CI $[6.9,8.8]$. Of more interest was the test of the $\mathrm{AD}$ and $\mathrm{BC}$ compounds on day 11 following shocked exposures to the $\mathrm{AB}$ compound on day 10. As shown in Figure $3 \mathrm{~B}$, averaged across all test presentations, freezing was greater to $\mathrm{AD}$ than to $\mathrm{BC}$. This difference was statistically significant, $F_{(1,15)}=10.9, P<0.01, \eta_{\mathrm{p}}^{2}=0.42,95 \%$ CI $[0.5,2.1]$.

The test compounds each contained an element that had been paired with the appetitive US (A and C) and an element that had been presented alone ( $B$ and $D)$. If tested before the shocked exposure to $\mathrm{AB}$, the appetitive response to the compounds would have been equivalent. Moreover, if an associative change across the shocked exposure to the $\mathrm{AB}$ compound was just regulated by a total or summed error term, then an equal change would have accrued to A and B. Hence, the logic of the design is that any differences in responses must be due to an unequal change to the $\mathrm{A}$ and $\mathrm{B}$ elements of the shocked exposures to $\mathrm{AB}$. In fact, the response (freezing) was greater to $\mathrm{AD}$ than to $\mathrm{BC}$, suggesting that the change was unequal: The element, $\mathrm{A}$, that had been paired with sucrose underwent more fear conditioning across the shocked exposures to the compound than the element, $\mathrm{B}$, that had been presented alone.

\section{Experiment 4}

There are at least two other explanations of the greater freezing to $\mathrm{AD}$ than to $\mathrm{BC}$ in the previous experiment. The first assumes that there was an equal change to the A-shock and B-shock associations across the compound conditioning trials and explains the differences in the test levels of freezing to associations formed between A and B across the compound conditioning trials (see Rescorla 2000, for discussion). These within-compound associations were such that $\mathrm{A}$ was encoded with the relatively neutral $B$, whereas B was encoded with the appetitive A. The consequence of these within-compound associations was that the A element of the $\mathrm{AD}$ compound activated a representation of the relatively neutral B, which exerted little effect on freezing, whereas the B element of the $\mathrm{BC}$ compound activated a representation of the appetitive A, which reduced freezing. The second alternative explanation again assumes an equal change to the A-shock and B-shock associations but appeals to the fact that $\mathrm{A}$ is tested in compound 

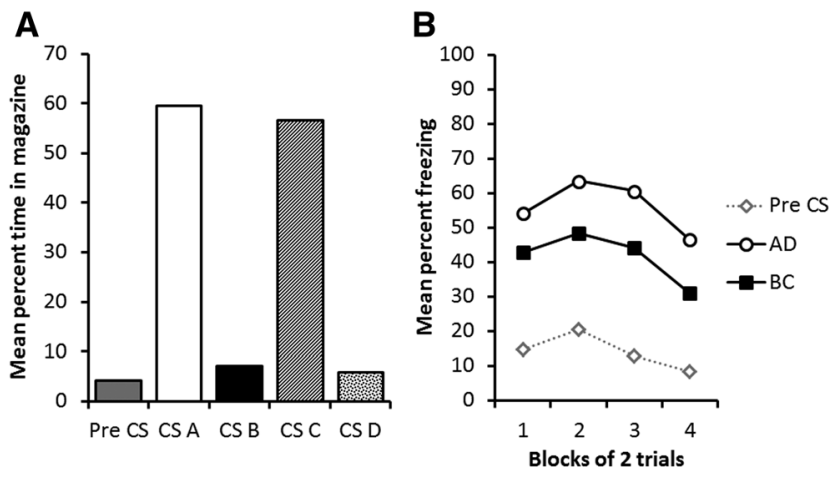

Figure 3. Results of Experiment 3. The mean percentage of time spent in magazine on the final trials of Stage 1 appetitive conditioning to conditioned stimuli (CSs) A, B, C, and D and in the 30-sec pre-CS periods $(A)$. The mean percentage of freezing during Stage 3 test to the $A D$ and $\mathrm{BC}$ compounds and in the $30-\mathrm{sec}$ pre-CS periods $(B)$.

with the relatively neutral $\mathrm{D}$ whereas $\mathrm{B}$ was tested in compound with the appetitive $\mathrm{C}$. Therefore, $\mathrm{D}$ exerted little or no impact on the freezing elicited by $A$ whereas $C$ reduced the freezing elicited by $\mathrm{B}$, leading to $\mathrm{AD}$ eliciting more freezing than $\mathrm{BC}$.

The present experiment examined these alternative explanations. The design again consisted in three stages. Stage 1 arranged that presentations of two CSs within a modality (e.g., visual) were each followed by sucrose (A-sucrose and C-sucrose) while two CSs from another modality (auditory) were each presented in the absence of sucrose (B- and D-). In Stage 2, rats received shocked exposures to a compound composed of one of the CSs paired with sucrose and one not paired with sucrose (AB-shock) as well as nonshocked exposures to a compound composed of the two other CSs, one that had been paired with sucrose and the other not paired with sucrose (CD-no shock). Finally, in Stage 3, rats were tested with compounds composed of $\mathrm{AD}$ and $\mathrm{BC}$.

Each of these compounds contained an element that had been paired with sucrose (A and C) and an element that had not been paired with sucrose (B and D). Moreover, each of the test compounds contained an element ( $B$ and $D$ ) that had been presented in compound with a CS paired with sucrose (A and C, respectively), thereby controlling for any effect of within-compound associations on the test levels of freezing. However, there is evidence that the formation of associations between the two elements of a simultaneous compound can be disrupted when the compound is followed by a US relative to when the compound is presented alone (Cheatle and Rudy 1978). Such evidence would suggest, therefore, the association between the A and B elements of the shocked compound would be less than that between the $\mathrm{C}$ and D elements of the nonshocked CD compound. If so, then on test, $\mathrm{D}$ would be more able than $\mathrm{B}$ to depress freezing via their appetitive associates, $\mathrm{C}$ and $\mathrm{A}$, respectively, Hence, freezing should be less to AD than to BC. Finally, the appetitive CSs, A and $\mathrm{C}$, were each presented in the absence of sucrose, thereby potentially controlling for the influence of the original appetitive values of $\mathrm{A}$ and $\mathrm{C}$ on the test levels of freezing. If the differences in the levels of freezing to $\mathrm{AD}$ and $\mathrm{BC}$ in the previous experiment were due to the influence of within-compound associations, then freezing in this experiment should be less to $\mathrm{AD}$ than to $\mathrm{BC}$; if the previous differences were due to the appetitive value of $C$, then the levels of freezing to $\mathrm{AD}$ and $\mathrm{BC}$ here should be equivalent. Alternatively, if the differences in the previous experiment were due to an unequal change across the shocked exposures to $A B$, then freezing will again be greater to $\mathrm{AD}$ than $\mathrm{BC}$.

Initial appetitive discrimination training proceeded smoothly. As shown in Figure 4A, by the final trials on day 9, the mean percent time spent in magazine during the reinforced $A$ and $C$ presentations was substantially greater than that during the nonreinforced $\mathrm{B}$ and $\mathrm{D}$ presentations. This difference between responses to $\mathrm{A}$ and $\mathrm{C}$ versus that to $\mathrm{B}$ and $\mathrm{D}$ was statistically significant, $F_{(1,15)}=289.4, P<0.00001, \eta_{\mathrm{p}}^{2}=0.95,95 \%$ CI $[5.8,7.5]$. During Stage 2, rats discriminated between the shocked $A B$ compound and the nonshocked $\mathrm{CD}$ compound. On the final trials, the mean percent freezing to $\mathrm{AB}$ was $82.2 \%$ whereas that to $\mathrm{CD}$ was $31.3 \%$. This difference was statistically significant, $F_{(1,15)}=79.6$, $P<0.00001, \eta_{\mathrm{p}}^{2}=0.84,95 \%$ CI $[2.5,4.1]$.

Of major interest was the test response to the $\mathrm{AD}$ and $\mathrm{BC}$ compounds on day 11 following shocked exposures to $A B$ as well as nonshocked exposures to $\mathrm{CD}$ the previous day. As shown in Figure $4 \mathrm{~B}$, the response was greater to $\mathrm{AD}$ than to $\mathrm{BC}$. This difference was statistically significant, $F_{(1,15)}=12.7, P<0.005$, $\eta_{\mathrm{p}}^{2}=0.46,95 \%$ CI $[0.5,1.8]$.

These results are consistent with the proposal that an unequal change accrues to the elements of a shocked compound when these elements enter the compound with different associative values: more changes accrued to the element, A, previously paired with the appetitive US than to the element, B, previously presented in the absence of sucrose. The test compounds were composed of elements equated for their histories: each contained appetitively reinforced (A and C) and nonreinforced (B and D) elements; each contained shocked (A and B) and nonshocked elements ( $C$ and $D$ ); each contained elements presented in compound (A with B and C with D); finally, the appetitive CSs, $A$ and $C$, were equated for their presentations in the absence of sucrose.

\section{Discussion}

These experiments have provided evidence that error correction mechanisms regulate appetitive-aversive interactions. In Experiment 1, moderately hungry rats were exposed to two stimuli and presented with an appetitive US (sucrose) in the presence of one (A) but not the other (B). Rats subsequently exposed to a shocked compound composed of A and a novel stimulus (X) acquired fear (freezing) more rapidly than those shocked to a $\mathrm{BX}$ compound and, critically, rats conditioned to the AX compound froze more when tested with $X$ than rats conditioned to $\mathrm{BX}$. The presence of the appetitive excitor (A) enhanced fear conditioning of its novel associate $(\mathrm{X})$ and/or the presence of the (potentially) appetitive inhibitor (B) reduced fear conditioning of $\mathrm{X}$. These results with freezing as a measure of conditioned fear replicate those found with conditioned suppression of
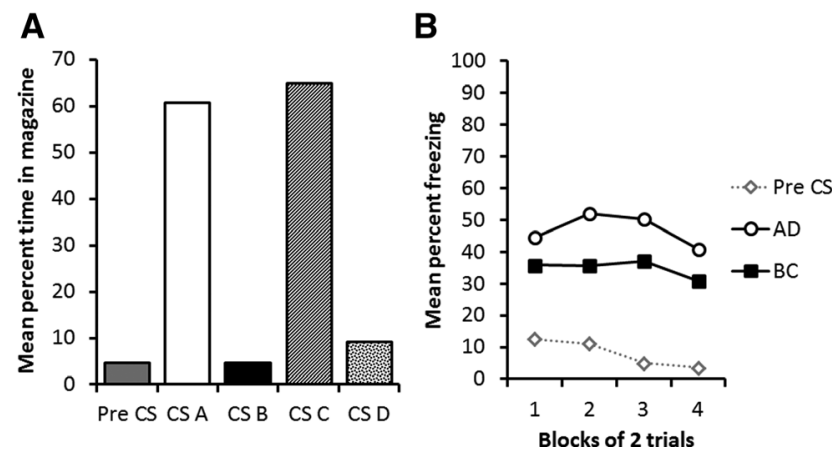

Figure 4. Results of Experiment 4. The mean percentage of time spent in magazine on the final trials of Stage 1 appetitive conditioning to conditioned stimuli (CSs) A, B, C, and D and in the 30-sec pre-CS periods $(A)$. The mean percentage of freezing during Stage 3 test to the $A D$ and $B C$ compounds and in the $30-$ sec pre-CS periods $(B)$. 
food-reinforced lever pressing. Dickinson (1977) reported that an appetitive excitor enhanced conditioning while Dickinson and Dearing (1979) reported that an appetitive inhibitor reduced fear conditioning to their novel associates in a shocked compound relative to the fear conditioned to the associate of a randomly presented stimulus.

Dickinson and Dearing (1979) noted that the contrasting effects of an appetitive excitor and appetitive inhibitor on fear conditioning to a target CS parallel the effects of an aversive inhibitor and aversive excitor, respectively: The appetitive excitor functions like an aversive inhibitor to enhance fear conditioning of its associate (Rescorla 1971) whereas the appetitive inhibitor acts like an aversive excitor to block that fear (Kamin 1968). Following a proposal by Konorski (1967), and in the tradition of other opponentprocess theories of motivation (e.g., Bindra 1974; Gray 1975), Dickinson and Dearing (1979) explained the equivalences just noted by proposing that pairings of a CS and a US result in the CS forming independent excitatory links to the sensory representation of the US and its affective or motivational properties. Thus, a CS paired with an attractive US comes to excite a positive, appetitive motivational state or system; whereas one paired with a noxious US comes to excite a negative, aversive motivational system (for review, see Dickinson and Pearce 1977). They further propose that a CS signaling the omission of an attractive US excites the negative, aversive system (it elicits frustration); and one that signals the omission of a noxious US excites the positive, appetitive system (it elicits relief). Finally, these states are opposite in that excitation of an appetitive state reduces an existing aversive state, and excitation of an aversive state reduces an existing appetitive state.

According to this type of opponent-process model, therefore, an appetitive inhibitor or an aversive excitor each blocks fear conditioning of their novel associate in a shocked compound because the discrepancy between the aversive state conditionally excited by the compound and that elicited by the noxious US is small, hence, the excitatory change is reduced. Conversely, an appetitive excitor or an aversive inhibitor enhances fear conditioning of their novel associate in the shocked compound because the discrepancy between the appetitive state conditionally elicited by the compound and the aversive state elicited unconditionally by the noxious US is large, hence the excitatory change is increased.

This model can also be applied to the results of Experiment 2. In that experiment, rats were again exposed to two stimuli, one of which, A, was paired with sucrose, and the other, B, presented in the absence of sucrose. Rats then received pairings of a third stimulus, $X$, and foot shock, extinguished to $\mathrm{X}$ in compound with either $\mathrm{A}$ or $\mathrm{B}$, and finally tested with $\mathrm{X}$. The test revealed that rats extinguished to $\mathrm{X}$ in compound with $\mathrm{A}$ froze more than those extinguished to $\mathrm{X}$ in compound with $\mathrm{B}$, indicating that the appetitive excitor, $\mathrm{A}$, had blocked extinction of $\mathrm{X}$ and/ or the (potentially) appetitive inhibitor, B, had enhanced extinction of X. These effects on fear extinction extend the parallels between appetitive excitors and aversive inhibitors on the one hand, and appetitive inhibitors and aversive excitors on the other hand. According to the model, the two CSs within each pair (appetitive excitor/aversive inhibitor and appetitive inhibitor/aversive excitor) exert the same effect on fear extinction, and the two pairs exert the opposite effect: The appetitive excitor and the aversive inhibitor impair (e.g., McConnell and Miller 2010), while the appetitive inhibitor and the aversive excitor enhance extinction of their fear-eliciting associate in a nonshocked compound (e.g., Rescorla 2006; Leung et al. 2012). These effects occur because nonshocked presentations of a compound composed of a feareliciting CS and either an appetitive excitor or an aversive inhibitor elicit a net affective value close to zero: the CS previously paired with shock excites an aversive state whereas the appetitive excitor or the aversive inhibitor excites an appetitive state. These states negate each other with the consequence that there is little or no discrepancy between the motivational state elicited by the compound and that appropriate to the outcome (nothing) across the nonshocked compound presentations. Hence, there is little or no associative change and extinction of the fear-eliciting CS is impaired. In contrast, nonshocked exposures to a compound composed of a dangerous $\mathrm{X}$ and either another aversive excitor or an appetitive inhibitor will summate in their activation of the aversive state, leading to a large discrepancy between the conditionally elicited state and that appropriate to the outcome (nothing) across the compound extinction trials. Hence, an associative change underlying extinction of $\mathrm{X}$ will be enhanced. This outcome has been demonstrated in the case of a concurrent aversive excitor (Rescorla 2006; Leung et al. 2012), but it has yet to be shown that the presence of an appetitive inhibitor facilitates extinction of its dangerous associate across nonshocked compound presentations relative to extinction of a second dangerous CS in isolation.

Experiments 3 and 4 provided evidence that the amount of associative change accruing to the elements of a shocked compound is also regulated by the discrepancy between the affective state elicited by the noxious US and the affective value of each element in the compound: The element, A, which had been paired with the appetitive US in Stage 1, received more of the associative change from the aversive US in Stage 2 than the element B that had been presented alone in Stage 1 . This result suggests that an associative change to the elements of a reinforced compound is unequal with a greater change accruing to the element whose starting value is more discrepant from the amount of change supported by the reinforcer. This suggestion is consistent with the results of a series of experiments by Rescorla $(2000,2001,2002)$. For example, one such experiment (Rescorla 2000) showed that when a compound composed of an appetitive excitor and an appetitive inhibitor was paired with food, the inhibitor underwent more associative changes than the excitor, despite the common observation that excitatory conditioning of an established conditioned inhibitor typically retards the appearance of overt conditioned response to the inhibitor. Rescorla argued that the commonly observed retardation effect is not due to a slower rate of associative change to the inhibitor. Rather, the lower initial value of a conditioned inhibitor actually enhances the associative change due to the large discrepancy between its starting value and the amount of change supported by the US even though the inhibitor fails to elicit response due to an increase in the threshold at which the associative change is expressed in performance.

The present experiments did not assess whether the development of freezing was retarded across pairings of the appetitive CS, A, with shock relative to pairings of the control stimulus, B, and shock. In fact, the results of Experiment 1 indicated that freezing developed more rapidly when A was shocked in compound with a novel stimulus, $X$, than when B was shocked in compound with $\mathrm{X}$. Regardless, Experiments 3 and 4 used the compound test procedure to provide evidence consistent with Rescorla's proposal that the associative change is proportional to the initial starting values of the elements in a reinforced compound. The novel finding here, of course, is that a history of appetitive conditioning results in a CS whose starting value across shocked exposures to a compound is lower than an equally familiar control stimulus lacking affective properties.

It is worth noting that aspects of the present findings can be explained in other ways. For example, the design used in Experiment 4 consisted in shocked exposures to a compound (AB-shock) composed of an element, A, previously paired with sucrose, and an element, B, previously presented alone, as well 
as nonshocked exposures to a compound (CD-) composed of two other elements, one, $\mathrm{C}$, previously paired with sucrose, and the other, D, previously presented alone. Subsequent to this Stage 2 training, the test of compounds composed of $\mathrm{AD}$ and $\mathrm{BC}$ revealed greater freezing to $\mathrm{AD}$ than $\mathrm{BC}$, indicating that greater fear had accrued to A than B across the shocked exposures to the $\mathrm{AB}$ compound. However, an alternative explanation of this difference in the test levels of freezing appeals to differences in the strengths of the A-sucrose and C-sucrose associations. That is, although both $\mathrm{A}$ and $\mathrm{C}$ were presented in the absence of their sucrose associate across Stage 2, AB-shock pairings may have facilitated (or deepened) extinction of the A-sucrose association relative to the effect of the $\mathrm{CD}$ alone presentations on extinction of the $\mathrm{C}$-sucrose association, and therefore, freezing was greater to $\mathrm{AD}$ than to BC. While this is logically possible, we are unaware of any evidence that pairing an appetitive CS with an aversive shock US deepens extinction of the CS-appetitive US association relative to simple presentations of the appetitive CS alone.

Finally, the present results may have translational implications. The demonstration that an appetitive CS enhances fear acquisition suggests that a traumatic experience in the presence of an otherwise appetitive or attractive set of cues may be more likely to enhance conditioned fear while extinction of conditioned fear in the presence of such cues may be less successful than in their absence.

\section{Materials and Methods}

\section{Subjects}

The subjects were experimentally naive adult male Wistar rats (Rattus norvegicus) weighting between 350 and $500 \mathrm{~g}$. They were obtained from the colony maintained by Animal Resources Centre (Perth, Australia) and were housed in plastic boxes $(67 \times$ $40 \times 22 \mathrm{~cm}$ ) with eight rats per box. The boxes were kept in an airconditioned colony room maintained on a 12-h light-dark cycle (lights on at 7:00 a.m.). Water was continuously available but chow was restricted to $15 \mathrm{~g}$ per rat per day to maintain bodyweight at $\sim 90 \%$ of free-feeding weight. Each rat was handled $2-3 \mathrm{~min}$ each day for $3 \mathrm{~d}$ prior to the start of the experiment. Experimental procedures were carried out between $10 \mathrm{a} . \mathrm{m}$. and $6 \mathrm{p} . \mathrm{m}$. The procedures were approved by the Animal Ethics Committee of the University of New South Wales.

\begin{abstract}
Apparatus
A set of four chambers (Med Associates) was used. Each chamber measured $30 \mathrm{~cm}$ (height) $\times 24 \mathrm{~cm}$ (length) $\times 21 \mathrm{~cm}$ (width). The side walls were made of aluminum, and the back and front walls as well as the ceiling were made of clear Perspex. The floors consisted of stainless steel rods which were $3.8 \mathrm{~mm}$ in diameter, spaced $1.6 \mathrm{~cm}$ apart (center to center), and wired to a constantcurrent generator that could deliver shock. Each chamber was equipped with a pump fitted with a syringe that could deliver an $8 \%$ sucrose solution into a recessed magazine in the front wall. Each chamber also contained an auditory stimulus generator that could deliver a $1-\mathrm{kHz}$ tone stimulus, a solenoid that could emit a 5-Hz clicker stimulus, stimulus lights, positioned on the same wall and to either side of the magazine, which could provide a constant visual stimulus, and a house light positioned on the opposite wall which could deliver a $3-\mathrm{Hz}$ flashing visual stimulus. Auditory stimuli were adjusted to $70 \mathrm{~dB}$ in the presence of a background noise of $40 \mathrm{~dB}$. All CSs were $30 \mathrm{sec}$ in duration. Each chamber was enclosed in a sound- and light-attenuating cabinet. The inside walls of the shells were painted black. A camera mounted on the back wall of each cabinet recorded the behavior of each rat. The camera was connected to a monitor and a DVD recorder in another room of the laboratory. An infrared light source illuminated each chamber $(940 \pm 25 \mathrm{~nm})$. All experimental events were
\end{abstract}

controlled by a microcomputer equipped with MED-PC software (Med Associates).

\section{Procedure}

\section{Experiment 1}

On day 1 , rats were given a 20-min magazine training session in which $0.1 \mathrm{~mL}$ of an $8 \%$ sucrose solution was delivered into the magazine on a variable-time $60-$ min schedule. On each of days $2-5$, rats received discrimination training with two visual stimuli (flashing or steady light, counterbalanced), each $30 \mathrm{sec}$ in duration, where sucrose was presented in the presence of one stimulus (designated A) on a variable-time 30 -sec schedule but not in the presence of the other stimulus (designated B). Each daily session contained eight reinforced trials of A and eight nonreinforced trials of B presented in an intermixed, pseudorandom order with the constraint that no more than two trials of the same type could occur consecutively. The intertrial interval, defined as stimulus offset to stimulus onset, was $2.5 \mathrm{~min}$. On day 6 , rats were randomly divided into two groups. One group (Group Super) received shocked presentations of a 30-sec compound composed of the visual stimulus A and a novel auditory stimulus (a tone, designated $\mathrm{X})$. Shock ( $0.5 \mathrm{~mA}$ intensity, $0.5 \mathrm{sec}$ duration) was delivered in the presence of AX on a variable-time 30-sec schedule. There were four AX-shock trials and the inter-trial interval was $5 \mathrm{~min}$. The other group (Group Control) received identical shocked exposures to the BX compound. On day 7, both groups were tested with the auditory stimulus, $\mathrm{X}$. The test consisted in eight presentations of $\mathrm{X}$, each $30 \mathrm{sec}$ in duration, spaced $2 \mathrm{~min}$ apart, in the absence of shock.

\section{Experiment 2}

On days $1-5$, the procedures for magazine training and appetitive conditioning were identical to Experiment 1 . On day 6, all rats received fear conditioning to an auditory stimulus (designated $\mathrm{X}$ ). This consisted in four presentations of $X$, each of which was shocked $(0.5 \mathrm{~mA}, 0.5 \mathrm{sec})$ once on a variable-time 30 -sec schedule. The intertrial interval was $5 \mathrm{~min}$. The rats were then randomly allocated to two groups. On each of days 7 and 8, one group of rats (Group Protect) received an extinction session consisting of 12 nonshocked AX compound presentations with an intertrial interval of $2.5 \mathrm{~min}$. On the same days, the other group (Group Control) received identical extinction training to the BX compound. On day 9 , both groups were tested for freezing to $X$ in the manner described in Experiment 1.

\section{Experiment 3}

On day 1 , all rats received a single magazine training session in the manner described previously. On days $2-9$, rats received appetitive discrimination training with four stimuli. Three of these stimuli were the same as those used in the previous experiments (constant light, flashing light and tone), while the fourth was a clicker. Two of these stimuli (designated A and C) were reinforced with a delivery of $0.1 \mathrm{~mL} 8 \%$ sucrose solution into the magazine and the other two (designated B and D) were nonreinforced. The reinforced stimuli were visual and the nonreinforced ones were auditory for half of the rats and the reverse for the remainder. Each daily session contained four trials of each stimulus and the reinforcement schedule was the variable-time 30-sec schedule described previously. The stimuli were presented in an intermixed, pseudorandom order with the constraint that no two trials of the same type could occur consecutively. The intertrial interval was $2.5 \mathrm{~min}$. On day 10, all rats received four shocked exposures to the $\mathrm{AB}$ compound. There was one footshock $(0.5 \mathrm{~mA}, 0.5 \mathrm{sec})$ per exposure delivered on a variable-time 30 -sec schedule. The intertrial interval was $5 \mathrm{~min}$. On day 11, rats were tested with compounds composed of $\mathrm{AD}$ and $\mathrm{BC}$ where each compound contained a constant element (constant light or tone) and an interrupted element (flashing light or click). The test was conducted in the manner described previously. 


\section{Experiment 4}

On days 1-9, the procedures for magazine training and appetitive conditioning were identical to Experiment 3. On day 10, all rats received four shocked exposures to the $\mathrm{AB}$ compound in the manner described, intermixed with four nonshocked exposures to the $\mathrm{CD}$ compound. The intertrial interval was $2.5 \mathrm{~min}$. On day 11, rats were tested with compounds composed of $\mathrm{AD}$ and $\mathrm{BC}$ in the manner described for Experiment 3.

\section{Scoring and statistics}

The behavior of each rat over the course of the experiment was recorded onto DVD and scored to determine the amount of time spent in the magazine or freezing during the stimulus presentations and the 30-sec period immediately before each presentation using a time sampling procedure. For appetitive discrimination training, each rat was scored every 2 sec for magazine entries, specifically, whether its head was in or out of the magazine. For aversive conditioning, each rat was scored every 2 sec for freezing, defined as the absence of all movements except those necessary for breathing (Fanselow 1980). The number of occasions on which the behavior was observed was expressed as a percentage of the total number of observations. Two observers, one of whom was naive to the purposes of the experiments, scored the DVDs. The correlation between their scores in this and subsequent experiments was high, $r>0.9$. Any inconsistencies in scoring were resolved in favor of the naive observer. The data were analyzed with planned orthogonal contrasts in analysis of variance. The Type I error rate was controlled at $\alpha=0.05$. Confidence intervals (95\% for the mean difference, standardized using the sample standard deviation) and a measure of effect size (partial $\eta^{2}$ ) are reported for each significant comparison.

\section{Acknowledgments}

The authors thank anonymous reviewers for their suggested improvements to the manuscript.

\section{Competing interest statement}

The authors declare no competing financial interests.

\section{References}

Bindra D. 1974. A motivational view of learning, performance, and behavior modification. Psychol Rev 81: 199-213.

Cheatle MD, Rudy JW. 1978. Analysis of second-order odor-aversion conditioning in neonatal rats: implications for Kamin's blocking effect. J Exp Psychol Anim Behav Process 4: 237-249.

Delamater AR, Westbrook RF. 2014. Psychological and neural mechanisms of experimental extinction: a selective review. Neurobiol Learn Mem 108: $38-51$.

Dickinson A. 1977. Appetitive-aversive interactions: superconditioning of fear by an appetitive CS. Q I Exp Psychol 29: 71-83.

Dickinson A, Dearing MF. 1979. Appetitive-aversive interactions and inhibitory processes. In Mechanism of learning and motivation (ed. Dickinson A, Boakes RA), pp. 203-231. Lawrence Erlbaum Associates, Hillsdale, NJ.
Dickinson A, Pearce JM. 1977. Inhibitory interactions between appetitive and aversive stimuli. Psychol Bull 84: 690-711.

Fanselow MS. 1980. Conditioned and unconditioned components of post-shock freezing. Pavlov J Biol Sci 15: 177-182.

Gray JA. 1975. Elements of a two-process theory of learning. Academic Press, London.

Kamin LJ. 1968. "Attention-like" processes in classical conditioning. In Miami symposium on the prediction of behavior: aversive stimulation (ed. Jones MR), pp. 9-33. University of Miami Press, Miami, FL.

Konorski J. 1967. Integrative activity of the brain. University of Chicago Press, Chicago.

Leung HT, Westbrook RF. 2010. Increased spontaneous recovery with increases in conditioned stimulus alone exposures. J Exp Psychol Anim Behav Process 36: 354-367.

Leung HT, Reeks LM, Westbrook RF. 2012. Two ways to deepen extinction and the difference between them. J Exp Psychol Anim Behav Process 38: 394-406.

Mackintosh NJ. 1975. A theory of attention: variations in the associability of stimuli with reinforcement. Psychol Rev 82: 276-298.

McConnell BL, Miller RR. 2010. Protection from extinction provided by a conditioned inhibitor. Learn Behav 38: 68-79.

Navarro JI, Hallam SC, Matzel LD, Miller RR. 1989. Superconditioning and overshadowing. Learn Motiv 20: $130-152$.

Pearce JM, Hall G. 1980. A model for Pavlovian learning: variations in the effectiveness of conditioned but not of unconditioned stimuli. Psychol Rev 87: 532-552.

Rescorla RA. 1971. Variations in the effectiveness of reinforcement and nonreinforcement following prior inhibitory conditioning. Learn Motiv 2: $113-123$.

Rescorla RA. 2000. Associative changes in excitors and inhibitors differ when they are conditioned in compound. J Exp Psychol Anim Behav Process 26: $428-438$.

Rescorla RA. 2001. Unequal associative changes when excitors and neutral stimuli are conditioned in compound. Q J Exp Psychol B 54: 53-68.

Rescorla RA. 2002. Comparison of the rates of associative change during acquisition and extinction. J Exp Psychol Anim Behav Process 28: 406-415.

Rescorla RA. 2006. Deepened extinction from compound stimulus presentation. J Exp Psychol Anim Behav Process 32: 135-144.

Rescorla RA, Wagner AR. 1972. A theory of Pavlovian conditioning: variations in the effectiveness of reinforcement and nonreinforcement. In Classical conditioning II: current research and theory (ed. Black $\mathrm{AH}$, Prokasy WF), pp. 64-99. Appleton-Century-Croft, New York, NY.

Rosen JB, Schulkin J. 1998. From normal fear to pathological anxiety. Psychol Rev 105: 325-350.

Soltysik SC, Wolfe GE, Nicholas T, Wilson WJ, Garcia-Sanchez JL. 1983. Blocking of inhibitory conditioning within a serial conditioned stimulus-conditioned inhibitor compound: maintenance of acquired behavior without an unconditioned stimulus. Learn Motiv 14: 1-29.

Urushihara K, Wheeler DS, Pineno O, Miller RR. 2005. An extended comparator hypothesis account of superconditioning. J Exp Psychol Anim Behav Process 31: 184-198.

VanElzakker MB, Dahlgren MK, Davis FC, Dubois S, Shin LM. 2014. From Pavlov to PTSD: the extinction of conditioned fear in rodents, humans and anxiety disorders. Neurobiol Learn Mem 113: 3-18.

Wagner AR. 1981. SOP: A model of automatic memory processing in animal behavior. In Information processing in animals: memory mechanisms (ed. Spear NE, Miller RR), pp. 5-47. Erlbaum, Hillsdale, NJ.

Wagner AR, Rescorla RA. 1972. Inhibition in Pavlovian conditioning: application of a theory. In Inhibition and learning (ed. Halliday MS), pp. 301-336. Academic Press, London.

Received September 24, 2015; accepted in revised form December 18, 2015. 


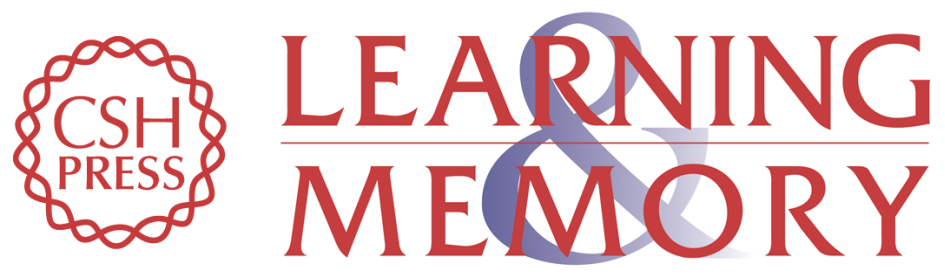

\section{An appetitive conditioned stimulus enhances fear acquisition and impairs fear extinction}

Hiu T. Leung, Nathan M. Holmes and R. Frederick Westbrook

Learn. Mem. 2016, 23:

Access the most recent version at doi:10.1101/Im.040337.115

$\begin{aligned} & \begin{array}{r}\text { Creative } \\ \text { Commons } \\ \text { License }\end{array} \begin{array}{l}\text { This article is distributed exclusively by Cold Spring Harbor Laboratory Press for the } \\ \text { first } 12 \text { months after the full-issue publication date (see } \\ \text { http://learnmem.cshlp.org/site/misc/terms.xhtml). After } 12 \text { months, it is available under } \\ \text { a Creative Commons License (Attribution-NonCommercial } 4.0 \text { International), as } \\ \text { described at http://creativecommons.org/licenses/by-nc/4.0/. }\end{array} \\ & \begin{array}{c}\text { Receive free email alerts when new articles cite this article - sign up in the box at the } \\ \text { top right corner of the article or click here. }\end{array} \\ & \begin{array}{c}\text { Service } \\ \hline\end{array}\end{aligned}$

